\title{
Chapter 15 \\ Gender Integration in Earth \\ Observation and Geo-information \\ Technology Applications: Correlation and Connections
}

\author{
Chanda Gurung Goodrich, Kamala Gurung, and Menaka Hamal
}

\subsection{Introduction}

As technological innovation and advancement is sweeping across the world, transforming economies, countries, and societies, Earth observation (EO) and geo-information technologies (GIT) have come closer to the public realm and become exceedingly an all-encompassing part in the daily lives of people, with more uses and users. These technologies today are not just "research and visualization tools", but they touch upon all aspects of people's lives, bringing in advantages as well as challenges for different groups of people (McLafferty 2005:38). These technologies and applications present opportunities for people to get information, to connect to one another, to explore and link to new markets and new areas of resource pools which could lead to innovations, increase efficiency and productivity, and also help in the delivery of effective public services (World Bank 2019). These technologies and applications can also be used by people, institutions, and corporations to exercise power over others, and it could influence gendered social relations and spaces in all spheres-social, economic, and political (McLafferty 2005; Stephens 2013). Thus, EO and GIT have significant implications for social and economic development, as well as for human rights and gender and social equality as they "can be engines of economic growth, offering new possibilities in health care, education, communication and productivity" - for example, a case of health, with the application of EO and GIT, can be built on geospatial data to track virus spread, identify vulnerabilities, manage facilities, and target responses

C. G. Goodrich $(\bowtie) \cdot$ K. Gurung $\cdot$ M. Hamal

International Centre for Integrated Mountain Development, Kathmandu, Nepal

e-mail: chanda.goodrich@icimod.org

(C) The Author(s) 2021

B. Bajracharya et al. (eds.), Earth Observation Science and Applications for Risk

Reduction and Enhanced Resilience in Hindu Kush Himalaya Region,

https://doi.org/10.1007/978-3-030-73569-2_15 
(United Nations 2020:2). Therefore, geospatial information is the foundation for various social and economic development activities, apart from its commercial uses (Ibid).

Technologies are set in the dynamics of the prevalent gender, social, and economic relations, which influence how the technologies are developed and how, where, and by whom they are used (McLafferty 2005). The prevalent unequal power relations between women and men from different socioeconomic backgrounds are bound to influence the development of, access to, and control over these technologies as well as the impacts they will have on them. Therefore, it is critical to expand our view and consider how these technologies are connected with the everyday lives of women and men in the society, given their position, status, and location. This means that it is crucial to explore and examine the correlations and connections between gender and EO and GIT.

This chapter seeks to explore the connections between gender and technology over the decades, examine the correlation between gender and EO and GIT, and discuss how SERVIR-HKH integrates gender concerns in its programs and activities.

\subsection{The Gender and Technology Question}

Links between gender and technology in terms of symbols, identities, access, control, and use have always been critical issues of discussion in the gender and development sector. This relationship between gender and technology has been shifting over time, but in general, "technology itself cannot be fully understood without reference to gender" (Cockburn and Ormrod 1993:32). Industrial capitalism associated technology with hegemonic masculinity, whereby technologies were for men - to be produced, wielded, and controlled by them (Caputi 1988; Faulkner 2001). Vast advances have been made in technology, particularly EO and GIT, and similarly, much transformation is taking place in women's spaces in terms of their rights, education, roles, and relations at the household and community levels. As a result, the relationship between gender and the array of EO and GIT applications and tools have also undergone changes. Deliberations on the importance of these technologies and applications and on their social, political, and ethical implications began in the 1980s with the view that EO and GIT technologies can have both positive and negative impacts on the people, and that the nature of the impact varies depending on the social groups (Bourgue and Warren 1987; Harding 1986). However, more critical debates and discourses on these technologies and applications and their links to society emerged in the 1990s (Chrisman 1987; Craig et al. 2002).

During that time, the main thread of the gender and technology discourse, in terms of EO and GIT, revolved around pro-technology and anti-technology perspectives (Fig. 15.1). The pro-technology perspective viewed these technologies and applications as tools for liberating women from the drudgery-ridden daily tasks, 


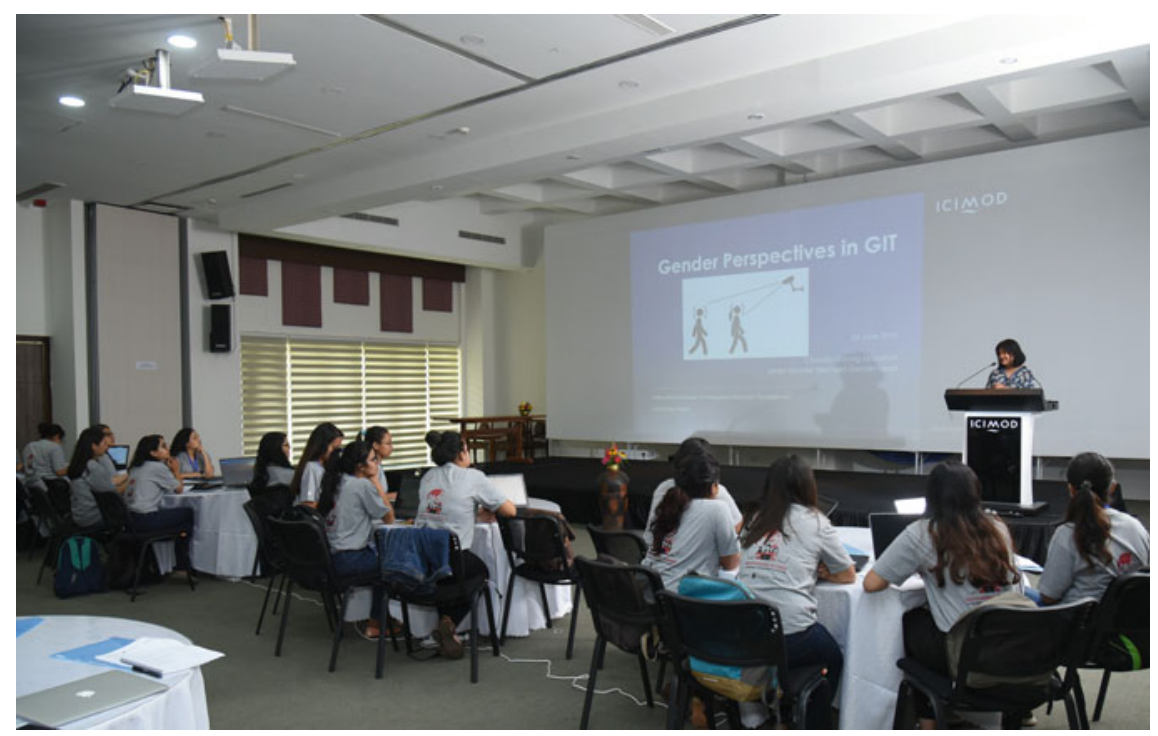

Fig. 15.1 Discourse on gender and GIT during a training event. Photo by Rajendra Shakya

while the anti-technology view regarded these technologies and applications as tools that perpetuate and reproduce gender inequality (Faulkner 2001). This more or less simple discourse then shifted to whether EO and GIT is masculinist or neutral in nature. These technologies and applications have often been termed as masculinist for the reason that they were mostly used for generating scientific knowledge for national defense, land management, and environmental assessmentsectors that were/are typically male dominated, which also rely only on secondary data, often not including social dimensions into the whole equation (Roberts and Schein 1995; Sheppard et al. 1999). The other view considers these technologies as gender neutral and not masculine and therefore can be positive for women in many aspects (Henwood 1993; Plant 1997; Oldenziel 1999). It is then argued that these technologies and applications rely on data exploration and layering and visualizations which can be used to construct and generate social and gender dimensions (Kwan 2002a; McLafferty 2005; Schuurman 2002).

Over time, the gender and technology discourse has moved away from these binary views, and the recent literature presents a more nuanced view that focuses on the social construction of technologies and their impacts on gendered social relations (Bray 2007; Faulkner 2001; McLafferty 2005; Wajcman 2000). Stemming from the view that both gender and technology are socially constructed and socially pervasive, this perspective would have it that there are "tight connections between them with technology shaping gender and gender shaping technology" (Lerman et al. 2003:5); and that the two are mutually constituted and "one cannot understand technology without reference to gender" and similarly, "one cannot understand gender without reference to technology" (Faulkner 2001:90). 
With this perspective, began the emergence of feminist scholarship within the field of technological studies and the use of the term "feminization" by McLafferty (2005:39) in the context of GIS; she argued that by bringing in changes in the use, construction, and application of GIS, technology can be rendered "more compatible with feminist understandings of research and practice". Several important GIS researchers also emphasize that community participation leads to a public participation GIS (PPGIS) platform which brings together diverse disciplines, including those of political economy, community development anthropology, political ecology, and the social sciences (Craig et al. 2002). These innovative efforts and initiatives have led to the incorporation of qualitative multimedia information into EO and GIT to complement each other and have allowed researchers to portray and reveal the multilayered and multifaceted dimensions of communities and places and give voice to the research subjects (Matthews et al. 2001). The influence of feminist geographers and social scientists has moved EO and GIT technologies far "beyond the detached, command-driven systems that predominated two decades ago", but this influence "is unevenly spread across" EO and GIT research and applications (McLafferty 2005:40).

\subsection{Gender and EO\&GIT: Without and Within}

EO and GIT technologies and applications are accessible to a wide range of users and touch people's lives closely. Hence, this calls for a closer look and analyses of the technologies as well as beyond their technological uses. Focusing only on the technology means to ignore those social, political, and economic structures of power that affect and shape these technologies and applications (Bosak and Schroeder 2005; Pavlovskaya 2018). Considering these technologies outside the "context of power" may not only reinforce the unequal power relations but also limit the role of these in "conservative social projects and stifle [the] progressive constructions" of these technologies (Pavlovskaya 2018:5). It is vital to (a) understand how technologies impact the lives of women and men, and how they influence and shape gendered social relations; and (b) examine how gender norms affect the development and content of, as well as access to, these technologies.

Therefore, we examine the gender and EO and GIT correlation from two aspects: broader gender concerns of access to and impacts of these technologies - we term this aspect "Without"; the inclusion or exclusion of gender concerns in the EO and GIT sector and content-we term this "Within".

\subsubsection{Without}

"Without" is used for the broader concerns that lie outside of the actual content and discipline of EO and GIT. Thus, this depicts the correlation between gender and EO 
and GIT in terms of the differential access to these technologies based on gender and social norms and practices and the differential impacts on the diverse gender and socioeconomic groups.

Access: Access to and control over resources is gendered (Gammage et al. 2016), and EO and GIT are very powerful and important resources as these applications offer a wide range of opportunities for instance, agriculture- and health-related information services. Gender norms and practices play an important role on who accesses these technologies. Due to this, access to and adoption of these technologies have not been uniform and vary based on gender, age, socioeconomic status, class, and geographic location. The gender structure and norms assign women a subordinate position vis-à-vis men, and they face numerous barriers in terms of finances, knowledge, skills, and mobility due to patriarchal relations in the household and community. For example, the gender division of labor plays a major role in the use of EO and GIT. Women, due to their conventional gender role of taking care of the household and family, which takes much of their time, are less likely to use these technologies and tools, whether it is for adding information (such as in maps) or for getting information (Liff et al. 2004; Stephens 2013). Another example is of people from lower socioeconomic groups having less access due to their financial status, while those living in remote locations also have a problem of access because of the non-availability of these technologies in their areas. Thus, access to such technologies is shaped by gender and social norms, economic (financial) resources, and geographical location (Kwan 2002b, c; McLafferty 2005). This has resulted in a nuanced digital divide between women and men, between socioeconomic classes, and between geographic locations, leaving those without access to these technologies more disadvantaged (United Nations 2020:2).

Impacts: EO and GIT have become more widespread with its uses ranging from complex and formal ones - such as for policy development and planning; management of resources, disasters, and risks; and warfare and surveillance - to the more common everyday uses such as for information, education, and shopping. This has extended the impacts of these technologies into many realms of everyday life. However, the impacts vary by gender as well as by age, class, and socioeconomic status since sociocultural norms and practices have a strong bearing on what kind of EO and GIT diverse people seek, how and for what they use them, and how they respond to these (Faulkner 2001; Chen et al. 2002). These technologies are influencing women and men's activities and behaviors and also changing their social and spatial interactions and boundaries.

EO and GIT are also being widely used for surveillance and monitoring by institutions, corporations as well as by individuals, which shows a clear link to power. Those in power are the ones who use the technologies for this purpose, and by doing so, it further augments their power (Haklay 2013; Leszczynski and Elwood 2015). This has enormous implications for both women and men, but there may be gender differences in the nature of the impacts. Women's greater domestic roles and responsibilities may make them more vulnerable than men to tracking by business houses in relation to purchases. There are numerous examples of how 
women's choices in household purchases are tracked, and based on this tracking, business houses flood women's social media and mailing sites with messages advertising the products they are likely to buy. These act as strong influencers on their choices and how they spend their money. At a more alarming level, the tracking systems can be used to perpetuate discriminatory and exploitative gender norms on women. For instance, exploitative partners, spouses, and family members can easily use these technologies to monitor women's movements and ensure their compliance with family or cultural norms and punish those women who violate these norms, thus reinforcing traditional gender roles and relations (Dobson and Fisher 2003).

Opportunities: EO and GIT tools and applications have the potential to reshape gender roles and relations in favor of women. These technologies open up many opportunities for women to ease their workload by enabling them to pursue alternative ways of carrying out household tasks; they also provide them with options to work remotely (Goyal 2011). This could lead to changes in the gender division of labor, and as with more time on their hands, women will get more opportunities to take up professional, paid work (Kotkin 2001). These technologies are also a valuable resource for social capital as they provide a huge scope for social networks (Boneva and Kraut 2002). They allow people to maintain and expand their contacts, which are particularly useful for women, giving them a sense of connectivity and support that can be empowering, given their lower mobility. This can be particularly significant for women in cases of domestic violence as the technologies can give them quick access to help and support. Another great example of EO and GIT as an opportunity for women is when these applications are used for gender-sensitive urban and town planning that respond to their needs and reduce spaces of violence. For instance, a simple streetlight can thwart violence. So, such technologies secure for women spaces they can safely operate in (Fenster 2005; Fesenko and Bibik 2017; Shirazi 2018; Carpio-Pinedo et al. 2019).

\subsubsection{Within}

The term "Within" is used for the aspects that fall inside or within the content, discipline, and sector of EO and GIT. Feminist geographers have indicated that power relations shape the construction and use of technologies such as EO and GIT, and that the development of these technologies in a particular context is influenced by the prevailing power relations (Sheppard et al. 1999). Thus, "Within" examines the questions of inclusion or exclusion of gender concerns in EO and GIT content, discipline, and sector.

The EO and GIT discipline is dominated by men, both in the academia and in the workforce (Haggar 2000; Schuurman 2002). The underlying reason for this is the gender structure whereby gender norms and practices that favor men have historically given men the edge with regard to education and technology. Despite efforts 
toward supporting more women to enter this discipline and profession, they are still lagging behind, particularly at the professional level in this field (Holmes et al. 2015; Bernard and Cooperdock 2018; UNESCO Institute of Science 2018; and Popp et al. 2019). Studies also show that women do not have great interest or confidence to work in this field (Rome's et al. 2007; Yau and Cheng 2012).

This compels the need to critically analyze how and in what ways such technologies and applications as well as the discipline and profession get gendered (Faulkner 2001). Many studies have shown how gender bias is widespread and ingrained in the discipline and profession itself. For instance: there still exists hiring biases against young women as they may leave the job or interrupt their careers to start a family, and this would impact scientific outputs (Williams and Ceci 2015); female geoscientists are more likely to experience negative gender bias at their workplaces and in scientific organizations than their male counterparts in the form of unequal opportunities in research funding/grants, less opportunity to get higher and prestigious scientific roles and positions (King et al. 2018; Vila-Concejo et al. 2018); the work environment usually is women-unfriendly since there is lack of flexibility in work timing and inadequate infrastructure to support working mothers; and there is also the issue of lack of same-gender role models, mentors, and women-oriented networks (Hill et al. 2010; Reuben et al. 2014; Holmes et al. 2015).

On the content side, the advances made in these technologies allow the public to contribute to the user-generated content of EO and GIT, especially with the new and welcome concepts of open access and citizen science. But yet, the shadow of male domination looms large. A study by Stephens (2013:994) shows that there is a gendered difference in the quantity of contributions and "this gendered differentiation manifests with women as users of the maps and men as expert reviewers of local knowledge, which has the potential to reproduce and reinforce the gender inequalities because men who document their local knowledge are documenting their own norms, traditions and biases".

On the positive side, EO and GIT open up new information, data, understandings, and innovations that are valuable process-questioning and problem-solving tools when applied as an integrated and thematic-based application (e.g., in the cases of forestry and drinking water); this can be used in a range of sectors and to address critical issues that are faced by communities and governments (Sharp 2005; McGinn and Duever 2018). These technologies can support integrated evaluations of the gender dimensions of any sector through a combination of tools and applications (Walker and Vajjhala 2011). There are now growing efforts to incorporate and overlay gender-related qualitative information on EO and GIT which are contributing to the increasing interface of gender with these technologies (SERVIR-Mekong 2015). These tools are now being extensively applied by organizations and governments in areas such as transport, health, urban and environmental planning, and disaster risk management. Along with these, it is critical to integrate gender to address the issues of the most vulnerable and marginalized groups in society (Kwan 2002c; Walker and Vajjhala 2011; Shirazi 2018; Carpio-Pinedo et al. 2019). 
It is self-evident that EO and GIT can promote and enable social transformation in important ways, such as by empowering women and marginalized groups, transforming gendered spaces, and by creating opportunities for a wider section of people to contribute to scientific content, advocacy, and to the establishment and running of community organizations and networks (Elwood 2008; Coulton et al. 2011; Pavlovskaya 2018).

\subsection{Engendering the SERVIR-HKH Program}

Gender is taken as a critical aspect in SERVIR Global, of which SERVIR-HKH is a part of, and in ICIMOD, wherein SERVIR-HKH is housed. SERVIR Global advocates and promotes interface of its services with inclusion of gender and social issues. It has also formed a SERVIR Network Gender Strategy with the overall goal to capture and disseminate lessons on improving gender equality, specifically with respect to making GIS/RS technologies and professions more gender responsive and equal. On similar lines, ICIMOD, with its overarching vision of "improved well-being of men, women and children of the HKH" and a strategic goal of advancing gender equality and inclusive development, gives high priority to gender in all its programs, and gender is taken as a crosscutting thematic area. Thus, SERVIR-HKH is mandated to integrate gender in the program, including in its approach, activities, services, and products. Integrating the aspect of gender is also critical for SERVIR-HKH to achieve its goal of improving upon the sustainable use of EO and GIT for environmental management and enhancing the resilience of the vulnerable population to climate change in the $\mathrm{HKH}$ region.

Looking back at the past decades, there are two major projects where ICIMOD worked on integrated gender and social aspects in GIS. The first project took place in 1996-1997 as an assessment of the comparative development status of Nepal's districts; this was conducted in collaboration with the Netherlands Development Assistance (SNV-Nepal). The primary aim was to provide a means of selecting priority districts for development assistance. The study used GIS to map the indicators of development at the district level. Indicators were developed for each of the following four dimensions: poverty and deprivation; socioeconomic, institutional, and infrastructural development; women's empowerment; and natural resource endowment and management. These were combined with physical topography, i.e., slope steepness, to construct a development index for each district (ICIMOD 1997). The second project took place in 2003 when ICIMOD partnered with the Central Bureau of Statistics, Nepal, and SNV-Nepal to update the report using more recent data. The updated study used as much as possible the same indicators as in the previous study and also followed the same methodology so that the two studies would be comparable (ICIMOD 2003).

A more systematic and focused approach on integrating gender took shape more recently when SERVIR-HKH developed a gender strategy and a detailed gender action plan. The gender strategy was developed to ensure systematic and focused 
gender integration and guide the program. The gender strategy identified three areas of concern where there was a need to integrate gender: in content; in access; and in professional-level participation.

Content: Incorporating gender-related information into the content in terms of geospatial products, services, and applications was crucial so that these could be used as tools for raising awareness on gender-related issues, influencing policies, and enabling communities to minimize gender-unequal risks and thereby help address gender inequality for more sustainable development (SERVIR-Mekong 2015).

Access: The information and products generated by SERVIR-HKH should be accessible to all the different gender and social groups in society, irrespective of their educational, gender, and other socioeconomic status. Furthermore, the technical information available in the form of maps and other applications should be translated, tailored, and narrated in a language that is readable and understandable for people with limited knowledge on maps and applications. These are also critical to achieve the ultimate goal of SERVIR-HKH: connecting space to village. Moreover, this part of the strategy gives due weightage to effective dissemination channels and mechanisms that can reach out to women and different socioeconomic groups.

Professional participation: As discussed in Sect. 15.3.2, there is a visible gender gap at professional levels in the geospatial professions. Globally, the number of women professionals in the geospatial sector is minimal and same is the case with HKH. A study says that among the researchers in the world in this field, only $19 \%$ are women (UNESCO Institute of Science 2018). This study reports that although women's enrolment in bachelor's degree in the fields of science, technology, engineering, and mathematics is equal or even slightly higher than men, their number in higher studies is rather low. This indicates that while women have the enthusiasm to pursue a career in geospatial studies, they cannot sustain it at the higher level and build a career in research. Numerous studies, which are cited in Sect. 15.3.2, show that women face different hurdles compared to men at work. Thus, there is an urgent need for the HKH region to address the issue of women's representation at the professional level.

SERVIR-HKH has adopted a "services" approach for ensuring the effectiveness of its services to help developing countries resolve the challenges in the priority service areas. The approach, therefore, is to integrate gender in all the services and make these services gender (as also socially) sensitive and responsive. The strategy is to frame the services so as to address gender needs and concerns in content, interpretation, and analysis. This entails systematically considering and addressing gender disparities, constraints, and opportunities to ensure that: the services under each of the thematic areas are gender sensitive and responsive; the dissemination processes of the services are designed in such a way that they are accessible to women and men of various socioeconomic groups; and the approaches that are adopted are affirmative as to bridge the gender gap at the professional level. In this 
regard, three strategies were adopted to integrate gender in order to achieve the three strategic objectives:

(i) Integrate gender in the Theory of Change (ToC) and in the monitoring, evaluation, and learning plan:

Integrating gender in TOC and in the monitoring, evaluation, and learning plan is crucial as this paves the way to practically and realistically mainstream gender at all stages and activities of a program. Hence, the strategy of the SERVIR-HKH ToC is to appropriately consider and integrate gender by setting up, from the very beginning, gender targets wherever necessary and relevant and establish gender-disaggregated monitoring data to support gender analysis; this also entails documentation and sharing of gender integration in ToC. (More details on ToC are in Chap. 18.)

(ii) Combine various gender methods, tools, and sensitivities during service design and implementation:

It is essential to integrate the geospatial information with appropriate gender-disaggregated data for developing gender-sensitive/-responsive services. Therefore, while developing the services, the interpretation and analysis will not only limit to EO, but rather the ultimate conclusion will be drawn based on integrating the geospatial data with social and gender analysis. For instance, SERVIR-HKH aims to generate community-level gender-disaggregated data to inform gender-responsive policymaking in Nepal. The Community Forest User Groups (CFUGs) in Nepal are in a position to gather local-level data and insights, and there is also in place a new national policy that encourages more women to participate in their management. In this regard, in partnership with Hariyo Ban, data from specific districts in Nepal are being collected to understand how women's access to CFUG decision-making will have an impact on forest conditions, the types of natural resources the community focuses on managing or collecting, and on how the CFUGs spend the money that is collected.

SERVIR-HKH believes that gathering such data paves the way for analysis and can be used by the government to design appropriate gender-responsive policies to encourage further engagement of women in decision-making spaces. This data can also be used by the government to determine funding allocation to the CFUGs. Though the data collection process has not yet begun, SERVIR-HKH anticipates serving an important role in the Hariyo Ban project in the following ways: it hopes to address the quantitative data gap in the project, develop data visualizations using GIS services, and convincingly present the data to the government. SERVIR-HKH, through Hariyo Ban, aims to have a lasting impact on policymaking in Nepal.

In the user-engagement process too, gender dimensions will be taken into consideration. For SERVIR-HKH, users are mainly partners who are involved at the service level in the development of the products and services either as co-creators, co-designers, co-implementers, and as ultimate or potential beneficiaries.

For this, SERVIR-HKH will engage and partner not only with the government agencies that are the immediate users of the services, but also with the end 
beneficiaries such as federations and associations of women and men farmers, water and forest users' associations, and community disaster management groups. This will benefit by way of ensuring that the services incorporate gendered perspectives in the analysis and interpretation of the information that is produced. (More details on how user engagement considers the gender perspective are given in Chaps. 17 and 18.)

The dissemination of the information that is available from the services will also consider gender dimensions in various ways, such as preparing these in a language that is suitable for the ultimate users and also disseminate through user organizations via printed material and audio-visual media. (Details in Chap. 17.) Moreover, the most effective dissemination channels and mechanisms will be identified to reach out to women and other socioeconomic groups.

(iii) Build women's leadership and create gender champions in SERVIR:

As has been discussed in Sect. 15.3.2, the EO and GIT field is male dominated, and as long as women remain in low numbers in this field, the working environment will continue to be biased against them, and patriarchal attitudes and processes will continue to reign. Therefore, it is imperative that more women enter this field. The strategy for this is to proactively seek and recruit women in the sector by applying affirmative actions and a positive discriminatory policy; include women in trainings, workshops, and related events by reserving 33-50\% seats for them and bringing women as speakers and resource persons in seminars, conferences, and workshops; empower and support young women in this field through targeted capacity building programs; and build and foster gender champions within the SERVIR-HKH program.

In addition to the gender strategy, SERVIR-HKH has also developed a detailed gender action plan. In 2017, based on the recommendations of the gender audit of 2016, ICIMOD initiated the development of a gender plan of action for all its programs and initiatives as well as for the institution as a whole, with the aim of increasing gender responsiveness in its works and processes. The main goals of this are threefold: ensure gender integration at ICIMOD; operationalize the gender policy; and create an accountability mechanism. A detailed procedure was laid out to develop the gender action plan that began with the outcome statement of the regional program of ICIMOD associated with.

This procedure was followed rigorously by the programs, including SERVIR-HKH (Table 15.1). In this way, the gender strategy is used as a guide and approach to integrate the gender aspect in SERVIR-HKH, while the gender action plan outlines the objectives and actions, spells out the gender-specific indicators to monitor and track, lists the inputs and resources that are required, identifies the responsible person/team, and sets a timeline. The implementation of the gender action plan will come up for evaluation in 2021. This will investigate, through meetings/workshops, as to whether the targets and actions have been accomplished 
Table 15.1 Procedure for developing the gender action plan

\section{Procedure for developing the Gender Action Plan}

\begin{tabular}{|c|c|c|c|c|}
\hline \multirow{3}{*}{ Step 1} & \multirow{3}{*}{$\begin{array}{l}\text { Identify the dimensions of the stated outcome } \\
\text { Identify the gender issues in each of these } \\
\text { Given the issues, set gender-specific goals/ } \\
\text { objectives }\end{array}$} & \multicolumn{3}{|c|}{ Outcome statement } \\
\hline & & Dimensions & Gender issues & Objectives \\
\hline & & & & \\
\hline
\end{tabular}

\begin{tabular}{|c|c|c|c|c|c|c|}
\hline & $\begin{array}{l}\text { What are the challenges in meeting } \\
\text { the objectives? }\end{array}$ & Objectives & Challenges & Opportunities & Actions & Indicators \\
\hline Step 2 & $\begin{array}{l}\text { What are the opportunities? } \\
\text { What are the actions needed? } \\
\text { What are the indicators to monitor } \\
\text { and show progress? }\end{array}$ & & & & & \\
\hline
\end{tabular}

\begin{tabular}{|c|c|c|c|c|c|c|c|c|}
\hline \multirow{3}{*}{ Step 3} & \multirow{3}{*}{$\begin{array}{l}\text { What are the actions? } \\
\text { What resources are required? } \\
\text { Who will be responsible? } \\
\text { What will be the timeline? }\end{array}$} & \multirow{2}{*}{ Objectives } & \multirow{2}{*}{ Actions } & \multicolumn{3}{|c|}{ Resources } & \multirow[t]{2}{*}{ Responsibility } & \multirow[t]{2}{*}{ Timeline } \\
\hline & & & & Financial & Human & Other & & \\
\hline & & & & & & & & \\
\hline & & & & & & & & \\
\hline
\end{tabular}

and then submit a progress report to the Strategic Planning, Monitoring and Evaluation (SPME) Unit of ICIMOD.

\subsection{Conclusion}

With EO and GIT entering the public realm with more uses and users, there is no doubt that they made an immense impact on several spheres of people's lives. Exploring and examining the connections and correlations between EO and GIT and gender shed light on the interlinkages between the two. It is evident that even today, this sector is predominately male dominated, which is linked to the gender norms that are prevalent in society, due to which knowledge and products are often developed by men. However, it is also clear that this scenario is undergoing rapid changes. EO and GIT have gone through transformations over time with inputs from feminist geographers which have been (and are still being) enriched by incorporating novel ways of thinking, thereby signaling a shift from the priority accorded to the methods of dominant technology and quantitative data, to combining these with methods that allow incorporation of contextualized, qualitative 
information. And riding on such a merger, these technologies and applications can aid in informing, broadening, and visualizing additional, and sometimes new, information in gender and feminist studies and discourses.

For SERVIR-HKH, the connection between EO and GIT and gender and social issues lies in the fact that these applications and technologies, when combined with the methods that address the needs, interests, and priorities of women and other marginalized groups, can contribute to equitable socioeconomic development, poverty reduction, and increased resilience. An example of this has been given a section in this chapter on generating community-level gender-disaggregated data to inform gender-responsive policymaking in Nepal. SERVIR-HKH has effectively laid down the gender-integrated approach in its programs and activities. The challenge has been in getting the technical professionals to internalize these complex and nuanced understandings. This is compounded by the involvement of very few gender and social scientists (in terms of numbers and time) in the SERVIR-HKH project; this makes it difficult to ensure that the plans, steps, and activities laid down in the gender strategy are followed thoroughly.

One of the ways forward is to strengthen gender integration in the EO and GIT sector as well as SERVIR-HKH; this would mean roping in more gender and social scientists as part of a core group who are as closely involved as the technical professionals. Such a strategy would go a long way in making both sets of professionals understand each other's views, and then, they could move forward together in a meaningful way, whether by capacity building through various trainings and workshops or through other means that are tailored according to the needs of the activity, output, or outcome. In the HKH region where climatic and socioeconomic changes are having an adverse impact on natural resources and livelihoods, the need to integrate gender in EO and GIT is critical and urgent as this will bear two important results: It will enable researchers and practitioners to set better target interventions for women and men on the ground in a wider geographical space; and second, it can fashion the applications or services in an effective and powerful manner whereby there is heightened awareness about gender issues. All this will also contribute to empowerment and address gender inequality by enabling communities to minimize gender-based unequal risks in various contexts and situations (for instance, in the areas of disaster risk reduction and building adaptation and resilience). Thus, on a broader note, EO and GIT can serve as a catalyst for transformative change-by addressing the issues of gender and social inequality as well as the unfair power distribution systems that are at play, these technologies have the wherewithal to create a just and level-playing field. 


\section{References}

Bernard RE, Cooperdock EH (2018) No progress on diversity in 40 years. Nat Geosci 11(5):292295. https://doi.org/10.1038/s41561-018-0116-6

Boneva B, Kraut R (2002) Email, gender and personal relationships. In: Wellman B, Haythornthwaite C (eds) The internet in everyday life. Blackwell, Malden, MA, pp 372-403

Bosak K, Schroeder K (2005) Using geographic information systems (GIS) for gender and development. Development in practice, vol 15, no. 2. Routledge, Taylor \& Francis, pp 231237. ISSN: 09614524

Bourgue CS, Warren BK (1987) Technology, gender and development. Learning about women: gender, politics, and power (Fall, 1987), vol 116, no 4, pp 173-197

Bray F (2007) Gender and technology. Annu Rev Anthropol 36:37-53

Caputi Jane (1988) Seeing elephants: the myths of phallotechnology. Feminist Stud 14(3):487-524

Carpio-Pinedo J, Hurtado SDG, De Madariaga IS (2019) Gender mainstreaming in urban planning: the potential of geographic information systems and open data sources. Plann Theor Pract. https://doi.org/10.1080/14649357.2019.1598567

Chen W, Boase J, Wellman B (2002) The global villagers: comparing internet users and uses around the world. In: Wellman B, Haythornthwaite C (eds) The internet in everyday life. Blackwell, Malden, MA, pp 74-113

Chrisman NR (1987) Design of geographic information systems based on social and cultural goals. Photgrammetric Eng Remote Sens 53(10):1367-1370

Cockburn C, Ormrod S (1993) Gender and technology in the making. Sage, London

Coulton C, Chan T, Mikelbank K (2011) Finding place in community change initiatives: using GIS to uncover resident perceptions of their neighborhoods. J Commun Pract 19(1):10-28. https://doi.org/10.1080/10705422.2011.550258

Craig WJ, Harris TM, Weiner D (eds) (2002) Community participation and geographic information systems. Taylor and Francis, London

Dobson J, Fisher P (2003) Geoslavery. IEEE Technology and Society Magazine (spring), pp 4752

Elwood S (2008) Grassroots groups as stakeholders in spatial data infrastructures: challenges and opportunities for local data development and sharing. Int J Geogr Inf Sci 22(1/2):71-90

Faulkner W (2001) The technology question in feminism: a view from feminist technology studies. Women's Stud Int Forum 24:79-95

Fenster T (2005) The Right to the gendered city: different formations of belonging in everyday life. J Gender Stud 14(3):217-231. https://doi.org/10.1080/09589230500264109

Fesenko G, Bibik N (2017) The safe city: developing of GIS tools for gender-oriented monitoring (on the example of Kharkiv city, Ukraine). Information technology. Eastern-Eur J Enterp Technol 3/2(87). ISSN 1729-3774: 25

Gammage S, Kabeer N, van der Meulen Rodgers Y (2016) Voice and agency: where are we now? Feminist Econ 22(1):1-29. https://doi.org/10.1080/13545701.2015.1101308

Goyal A (2011) Developing women: why technology can help. Inf Technol Develop 17(2):112132. https://doi.org/10.1080/02681102.2010.537252

Haggar R (2000) GIS: gendered information systems. Paper read at the annual meeting of the association of american geographers, 6 April, Pittsburgh, PA

Haklay M (2013) Neogeography and the delusion of democratization. Environ Planning 45(1):5569

Harding S (1986) The science question in feminism. Cornell Univ. Press, Ithaca, NY

Henwood Flis (1993) Establishing gender perspectives on information technology: problems, issues and opportunities. In: Green E, Owen J, Pain D (eds) Gendered by design? Information technology and office systems. Taylor and Francis, London, pp 31-52

Hill C, Corbett C, St. Rose A (2010) Why so few? Women in science, technology, engineering, and mathematics. AAUW 
Holmes MA, O'Connell S, Dutt K (2015) Women in the geosciences—practical, positive practices toward parity. Wiley, Hoboken, New Jersey

International Centre for Integrated Mountain Development (ICIMOD) (1997) Districts of Nepal indicators of development. ICIMOD, Kathmandu

King L, MacKenzie L, Tadaki M, Cannon S, McFarlane K, Reid D, Koppes M (2018) Diversity in geoscience: Participation, behaviour, and the division of scientific labour at a Canadian geoscience conference. FACETS 3(1):415-440. https://doi.org/10.1139/facets-2017-0111

Kotkin J (2001) The new geography: how the digital revolutions reshaping the American landscape. Random House, New York

Kwan MP (2002a) Is GIS for women? Reflections on the critical discourse in the 1990s. Gender Place Culture 9:271-279

Kwan MP (2002b) Feminist visualization: re-envisioning GIS as a method in feminist geographic research. Ann Assoc Am Geogr 92:645-661

Kwan MP (2002c) Introduction: feminist geography and GIS. Gender Place Culture 9:261-262

Lerman NE, Oldenziel R, Mohun AP (2003) Introduction: interrogating boundaries. In: Lerman NE, Oldenziel R, Mohun AP (eds) Gender and technology — a reader. John Hopkins University Press, pp 1-9

Leszczynski A, Elwood S (2015) Feminist geographies of new spatial media. Can Geogr 59 (1):12-28

Liff S, Shepherd A, Wajcman J, Rice R, Hargittai E (2004) An evolving gender digital divide? OII Internet Issue Brief

Matthews S, Burton L, Detwiler J (2001) Viewing people and places: conceptual and methodological issues in coupling geographic information analysis and ethnographic research. Paper read at conference on GIS and critical geographic research, 25 February, New York, NY

McGinn E, Duever M (2018) Building maps: GIS and student engagement. Library Hi Tech News 35(4):9-12. https://doi.org/10.1108/LHTN-12-2017-0089

McLafferty S (2005) Women and GIS: geospatial technologies and feminist geographies. Cartographic Int J Geogr Inf Geovisualization 40(4):37-45. https://doi.org/10.3138/1341-21jt4p83-1651

Oldenziel R (1999) Making technology masculine: men, women and modern machines in America. Amsterdam University Press, Amsterdam

Pavlovskaya M (2018) Critical GIS as a tool for social transformation. Can Geogr Le Geographer Canadian 1-15. https://doi.org/10.1111/cag.12438

Plant Sadie (1997) Zeros and ones: digital women and the new technoculture. Fourth Estate, London

Popp AL, Lutz SR, Khatami S, van Emmerik THM, Knoben WJM (2019) Perceptions and impacts of gender inequality in the geosciences are strongly gendered. EarthArXiv Preprint

Reuben E, Sapienza P, Zingales L (2014) How stereotypes impair women's careers in science. PNAS 111(12):4403-4408. https://doi.org/10.1073/pnas.1314788111

Roberts S, Schein R (1995) Earth shattering: global imagery and GIS. In: Pickles J (ed) Ground truth: the social implications of geographic information systems. Guilford, New York, pp 171195

Rome's EWM, Overbeek G, Engels RCME, De Kemp RAT, Scholte RHJ (2007) 'I'm not interested in computers': gender-based occupational choices of adolescents. Inf Commun Soc 10(3):299-319

Schuurman N (2002) Women and technology in geography: a cyborg Manifesto for GIS. Can Geogr 46:262-265

SERVIR-Mekong (2015) Gender and GIS: guidance notes. Asian Disaster Preparedness Center, Bangkok, Thailand

Sharp J (2005) Geography and gender: feminist methodologies in collaboration and in the field. Prog Hum Geogr 29:304-309

Sheppard E, Couclelis H, Graham S, Harrington J, Onsrud H (1999) Geographies of the information society. Int J Geog Inf Sci 13:797-823 
Shirazi MR (2018) Mapping neighbourhood outdoor activities: space, time, gender and age. J Urban Des. https://doi.org/10.1080/13574809.2018.1458607

Stephens M (2013) Gender and the GeoWeb: divisions in the production of user-generated cartographic information. GeoJournal 78:981-996. https://doi.org/10.1007/s10708-013-9492-z

UNESCO Institute of Statistics (2018) Women in science. http://uis.unesco.org/apps/ visualisations/women-in-science/\#overview

United Nations (2020) World social report 2020 - inequality in a rapidly changing world. Department of Economic and Social Affairs, United Nations

Vila-Concejo A, Gallop SL, Hamylton SM, Esteves LS, Bryan KR, Delgado-Fernandez I, Splinter K (2018) Steps to improve gender diversity in coastal geoscience and engineering. Palgrave Common. 4(1):103. https://doi.org/10.1057/s41599-018-0154-0

Walker W, Vajjhala SP (2011) Gender and GIS: mapping the links between spatial exclusion, transport access and the millennium development goals in Lesotho, Ethiopia and Ghana. SSRN Electron J. http://doi.org/10.2139/ssrn.1473931

Wajcman J (2000) Reflections on gender and technology. In what state is the art? Soc Stud Sci 30:447-464

Williams WM, Ceci SJ (2015) National hiring experiments reveal 2:1 faculty preference for women on STEM tenure track. PNAS 112(17):5360-5365. https://doi.org/10.1073/pnas. 1418878112

World Bank (2019) World development report 2019: The changing nature of work. World Bank, Washington, DC. https://doi.org/10.1596/978-1-4648-1328-3 License: Creative Commons Attribution. CC BY 3.0 IGO

Yau HK, Cheng ALF (2012) Gender difference of confidence in using technology for learning. J Technol Stud 38(2):74-79. https://doi.org/10.21061/jots.v38i2.a.2

Open Access This chapter is licensed under the terms of the Creative Commons Attribution 4.0 International License (http://creativecommons.org/licenses/by/4.0/), which permits use, sharing, adaptation, distribution and reproduction in any medium or format, as long as you give appropriate credit to the original author(s) and the source, provide a link to the Creative Commons license and indicate if changes were made.

The images or other third party material in this chapter are included in the chapter's Creative Commons license, unless indicated otherwise in a credit line to the material. If material is not included in the chapter's Creative Commons license and your intended use is not permitted by statutory regulation or exceeds the permitted use, you will need to obtain permission directly from the copyright holder.

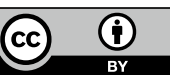

